\title{
Improving the Transition to Ophthalmology Residency: A Survey of First-Year Ophthalmology Residents
}

\author{
Akshay S. Thomas, MD, MS ${ }^{1}$ Travis Redd, MD, MPH ${ }^{1}$ Thomas Hwang, MD ${ }^{1}$ \\ ${ }^{1}$ Casey Eye Institute, Oregon Health \& Science University, \\ Address for correspondence Thomas Hwang, MD, Casey Eye Institute, \\ Portland, Oregon \\ Oregon Health \& Science University, 3375 SW Terwilliger Blvd., \\ Portland, OR 97239 (e-mail: hwangt@ohsu.edu). \\ J Clin Acad Ophthalmol 2016;8:e10-e18.
}

\begin{abstract}
Purpose The objective of this study is to quantify the impact of the transition from internship to ophthalmology residency and to identify practices that help ease this transition.

Methods An online questionnaire was developed with 21 questions focusing on areas felt to impact the transition to ophthalmology residency. This was sent to all program directors of accredited ophthalmology residency programs in the United States for distribution to their first-year trainees. Responses were tabulated and evaluated for associations using comparative statistics.

Results Ninety-one first-year residents responded. Fifty-five identified the transition to ophthalmologic training as more stressful than internship. Independent preparation $(p<0.01)$ and doing an ophthalmology rotation during internship $(p=0.04)$ significantly reduced stress, and those doing a transitional PGY-1 year were significantly more likely to do either $(p<0.01)$. Additionally, orientations dedicating more time to exam skills $(p<0.01)$ were associated with significantly lower stress, while residents who had relatively shorter buddy-call systems $(p=0.02)$ were significantly more stressed.

Conclusion This study identified the transition to ophthalmology residency as highly

Keywords

- residency

- stress

- orientation stressful for trainees. Time spent preparing for ophthalmology residency is crucial to easing this transition, and a transitional year affords more opportunity for such preparation. Orientations which provide more hands-on experience reduce stress among new residents, as do longer buddy-call systems.
\end{abstract}

Training to become a physician is a highly stressful and difficult undertaking. Particularly challenging are the transitions between sequential stages of the process. Nowhere is this more acute than in the transition from medical school to graduate medical training. New house officers encounter many new challenges, including an abrupt increase in responsibility, managing uncertainty, working as a team, and potential difficulty with socialization into a program. ${ }^{1,2}$ This stress subsequently confers an increased risk of depression and anxiety, which together may affect as many as 35\% of first-year residents across all specialties. ${ }^{3}$ These psychological sequelae can eventually contribute to early burnout. ${ }^{4,5}$

In ophthalmology training, a significant transition occurs at the beginning of ophthalmology residency. Residents switch from internship, where they mostly function in general medical or surgical wards-toward which much of their prior clinical education is directed-to ophthalmology residency, where medical school and internship contribute relatively little toward the development of a pertinent knowledge base and practical skills. ${ }^{6}$ Unfortunately, the literature to received

June 27, 2015

accepted after revision

February 10, 2016
DOI http://dx.doi.org/

10.1055/s-0036-1581109. ISSN 2379-0539.
Copyright $\odot 2016$ by Thieme Medical Publishers, Inc., 333 Seventh Avenue, New York, NY 10001, USA. Tel: +1(212) 584-4662.
License terms

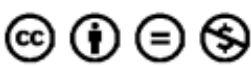


date provides no assessment of the impact of this transition on new ophthalmology residents.

Several techniques have been described to reduce the emotional strain of initiating residency training in other medical specialties. On an individual level, seeking social support, being problem-focused, and avoiding self-blame have been identified as successful techniques in reducing the burden of this transition. ${ }^{7}$ Trainees have also cited several program-level interventions as particularly helpful in reducing stress, including close supervision during the first few weeks and on call, avoidance of sleep deprivation, facilitated personal discussions with colleagues and supervisors, and adequate personal time with friends and family. ${ }^{7}$ In addition, several preparatory courses have also been employed by residency programs for trainees beginning internship in surgery $^{8,9}$ and medicine, ${ }^{10,11}$ resulting in increased preparedness and easier adaptation to postgraduate training. While these results apply specifically to the transition to internship in various nonophthalmologic medical fields, the results raise the possibility that similar personal- and systemlevel interventions might also be utilized to ease the transition to ophthalmology residency.

In this study, we surveyed current first-year ophthalmology residents in their initial months of training to assess the stress associated with the transition to the PGY-2 year. Additionally, we solicited examples of interventions they or their programs had employed to ease this transition, with the goal of informing both residents and residency programs how to better prepare for this transition.

\section{Methods}

\section{Survey Questionnaire}

An online survey was developed using a two-round modified Delphi survey involving a panel of four first-year ophthalmology residents. We chose not to use a validated instrument to measure stress, such as the Depression, Anxiety and Stress Scale (DASS), as the purpose of our survey was to measure the specific causes and interventions associated with stress among residents and not simply the prevalence of stress. After discussing the specific goals of the survey with the panel, the first round of the Delphi requested a list of events/ responsibilities that panelists found most stressful at the start of ophthalmology residency as well as a list of interventions that could have been implemented to reduce this stress. We used these responses to develop an online questionnaire focusing on three broad areas felt to impact the transition to ophthalmology residency: (1) preparation during PGY1 year; (2) orientation at the start of ophthalmology residency; and (3) the first 3 months of ophthalmology residency. All questions were in a multiple-choice format but also provided the option of free text entry. The second round of the Delphi had the panel rate individual questions on a scale of 0 to 5 , with 5 being the "most likely to impact or measure stress among ophthalmology residents." Questions with an average score less than 3 were deleted from the survey. We finally pilot tested the 21-question survey ( - Table 1 ) on the panel, and validated the survey based on adequate variance in responses with very few "other" responses, high compliance rate to survey directions, and feedback that the survey adequately measured what it had been designed to measure.

\section{Participants}

We targeted current first-year ophthalmology residents at accredited U.S. ophthalmology programs. This study was conducted in accordance with the tenets of the Declaration of Helsinki. After approval of the Institutional Review Board at Oregon Health \& Science University, we sent a link to the online questionnaire via email to all domestic residency program directors with a request that it be forwarded to current firstyear residents. This email was sent in early October 2013, and the survey link was closed 2 weeks later. We collected no demographic characteristics from participants to preserve anonymity and encourage honest responses.

\section{Statistical Analysis}

We generated frequency tables for responses to each question, and performed the Fisher exact test to identify associations between categorical questions of interest. This test was chosen over the $\chi^{2}$ test because the expected values for many cells were $<5$.

The primary outcome was resident stress level during the first 2 months of residency, which subjects ranked on a scale from 1 to 10 (10 being high) on the questionnaire. We considered this an ordinal rather than numerical scale, due to the absence of units and potential for variation in opinion of the magnitude of intervals between adjacent numbers on the scale. Therefore, we used nonparametric tests to evaluate potential associations between selected variables identified on the survey and stress level during early residency. For questions with ordinal answer choices, we used the Jonckheere-Terpstra test for ordered alternatives (Jonckheere trend test). We analyzed questions which allowed respondents to select more than one answer choice using Wilcoxon rank sum tests comparing all those who selected a given answer choice to all those who did not (and applied a Bonferroni correction for multiple comparisons to $p$-values). Finally, for simple categorical answer choices where only one answer could be selected per respondent and questions with ordinal answer choices of varying intervals, we used the Kruskal-Wallis equality-of-populations rank test.

We anticipated a response rate of at least $15 \%$ to ensure generalizability to the broader population of ophthalmology residents. We utilized Excel 2011 (Microsoft, Redmond, WA) for data management and Stata/SE 12 (StataCorp, College Station, TX) for all statistical analysis.

\section{Results}

Ninety-one first-year ophthalmology residents responded to the survey. It is unknown how many program directors forwarded the survey to all of their first-year residents, but assuming all 458 potential respondents ${ }^{12}$ received the survey, a highly conservative estimate of the response rate would be $20 \%$. The actual response rate is likely much higher, but cannot be precisely quantified. 
e12 Improving the Transition to Ophthalmology Residency Thomas et al.

Table 1 Survey responses of 91 first-year ophthalmology residents across the United States in 2013

\begin{tabular}{|c|c|}
\hline Survey question ${ }^{\mathrm{a}}$ & $n(\%)$ \\
\hline \multicolumn{2}{|l|}{ Intern year } \\
\hline \multicolumn{2}{|c|}{ 2. Which best describes your PGY-1 year? } \\
\hline Preliminary medicine & $48(53 \%)$ \\
\hline Transitional & $37(41 \%)$ \\
\hline Preliminary surgery & $5(5 \%)$ \\
\hline Other & $1(1 \%)$ \\
\hline \multicolumn{2}{|c|}{ 3. What type of independent preparation did you do for ophthalmology residency? ${ }^{\mathrm{b}}$} \\
\hline None & $29(32 \%)$ \\
\hline Textbook & $35(39 \%)$ \\
\hline Videos & $8(9 \%)$ \\
\hline Rotation & $49(54 \%)$ \\
\hline \multicolumn{2}{|c|}{ 4. On average, how many hours per week did you spend preparing for ophthalmology residency during your PGY-1 year? } \\
\hline$<1$ & $66(73 \%)$ \\
\hline 1 to 5 & $22(24 \%)$ \\
\hline 5 to 10 & $1(1 \%)$ \\
\hline$>10$ & $2(2 \%)$ \\
\hline \multicolumn{2}{|l|}{ Orientation experience } \\
\hline \multicolumn{2}{|c|}{ 5. How long was orientation at the start of ophthalmology residency? } \\
\hline$<1 \mathrm{wk}$ & $22(24 \%)$ \\
\hline 1 to 2 wk & $54(60 \%)$ \\
\hline$>2 \mathrm{wk}$ & $14(16 \%)$ \\
\hline \multicolumn{2}{|c|}{ 6. What percentage of orientation was spent on didactic information? } \\
\hline$<25 \%$ & $20(22 \%)$ \\
\hline 25 to $50 \%$ & $38(43 \%)$ \\
\hline$>50 \%$ & $31(35 \%)$ \\
\hline \multicolumn{2}{|c|}{ 7. What percentage of that time was spent practicing hands-on skills? } \\
\hline$<25 \%$ & $45(50 \%)$ \\
\hline 25 to $50 \%$ & $38(42 \%)$ \\
\hline$>50 \%$ & $7(8 \%)$ \\
\hline \multicolumn{2}{|c|}{ 8. Was there a time slot dedicated to relationship-building during orientation? } \\
\hline Yes & $63(70 \%)$ \\
\hline No & $27(30 \%)$ \\
\hline \multicolumn{2}{|c|}{ 9. Did you feel adequately oriented to facilities and logistics upon completion of orientation? } \\
\hline Yes & $43(48 \%)$ \\
\hline Somewhat & $42(47 \%)$ \\
\hline No & $5(6 \%)$ \\
\hline \multicolumn{2}{|c|}{ 10. What was the most beneficial part of orientation $?^{\text {b }}$} \\
\hline Practicing exam skills & $64(71 \%)$ \\
\hline Introductory lectures & $35(39 \%)$ \\
\hline Team-building sessions & $8(9 \%)$ \\
\hline Practicing basic surgical skills & $6(7 \%)$ \\
\hline Administrative-related topics & $2(2 \%)$ \\
\hline Other & $2(2 \%)$ \\
\hline
\end{tabular}


Table 1 (Continued)

\begin{tabular}{|c|c|}
\hline Survey question ${ }^{a}$ & $n(\%)$ \\
\hline \multicolumn{2}{|c|}{ 11. What was the least beneficial part of orientation? ${ }^{\text {b }}$} \\
\hline Practicing exam skills & $4(5 \%)$ \\
\hline Introductory lectures & $25(28 \%)$ \\
\hline Team-building sessions & $23(26 \%)$ \\
\hline Practicing basic surgical skills & $15(17 \%)$ \\
\hline Administrative-related topics & $14(16 \%)$ \\
\hline EHR-related topics & $2(2 \%)$ \\
\hline Nothing & $2(2 \%)$ \\
\hline Other & $4(5 \%)$ \\
\hline
\end{tabular}

12. Which didactic topic do you wish had been discussed in more detail? ${ }^{\mathrm{b}}$

\begin{tabular}{|l|l|}
\hline Basic eye exam & $38(42 \%)$ \\
\hline Ocular trauma & $23(26 \%)$ \\
\hline Common consult diagnoses & $56(62 \%)$ \\
\hline Surgical topics & $2(2 \%)$ \\
\hline Other & $2(2 \%)$ \\
\hline 13. Which exam skill do you wish had been addressed in more detail? ${ }^{\text {b }}$ & \\
\hline Autorefraction & $12(13 \%)$ \\
\hline Lensometry & $12(13 \%)$ \\
\hline Manifest refraction & $29(32 \%)$ \\
\hline Applanation tonometry & $22(24 \%)$ \\
\hline Pupillary exam & $9(10 \%)$ \\
\hline Confrontational visual fields & $6(7 \%)$ \\
\hline Anterior segment exam (slit lamp) & $24(27 \%)$ \\
\hline Posterior segment exam (slit lamp) & $36(40 \%)$ \\
\hline Posterior segment exam (indirect ophthalmoscopy) & $44(49 \%)$ \\
\hline Gonioscopy & $66(73 \%)$ \\
\hline
\end{tabular}

Early residency experience

14. Which exam skills did you feel adequately prepared for when you started seeing patients? ${ }^{\mathrm{b}}$

\begin{tabular}{|l|l|}
\hline Autorefraction & $31(35 \%)$ \\
\hline Lensometry & $29(33 \%)$ \\
\hline Applanation tonometry & $29(33 \%)$ \\
\hline Pupillary exam & $41(46 \%)$ \\
\hline Confrontational visual fields & $65(73 \%)$ \\
\hline Anterior segment exam (slit lamp) & $70(79 \%)$ \\
\hline Posterior segment exam (slit lamp) & $61(69 \%)$ \\
\hline Posterior segment exam (indirect ophthalmoscopy) & $30(34 \%)$ \\
\hline Gonioscopy & $24(27 \%)$ \\
\hline None & $6(7 \%)$ \\
\hline
\end{tabular}

16. What was the most stressful aspect of your first few weeks as a new resident? ${ }^{\mathrm{b}}$

\begin{tabular}{|l|l|}
\hline Call & $68(78 \%)$ \\
\hline Clinic responsibilities & $30(35 \%)$ \\
\hline Reading & $29(33 \%)$ \\
\hline
\end{tabular}


e14 Improving the Transition to Ophthalmology Residency Thomas et al.

Table 1 (Continued)

\begin{tabular}{|c|c|}
\hline Survey question ${ }^{\mathrm{a}}$ & $n(\%)$ \\
\hline City/new people & $5(6 \%)$ \\
\hline \multicolumn{2}{|c|}{ 17. Did you have a buddy-call system? If so, for how long? } \\
\hline No & $1(1 \%)$ \\
\hline$<1 \mathrm{mo}$ & $24(27 \%)$ \\
\hline 1 to $3 \mathrm{mo}$ & $49(56 \%)$ \\
\hline 3 to $6 \mathrm{mo}$ & $9(10 \%)$ \\
\hline$>6 \mathrm{mo}$ & $5(6 \%)$ \\
\hline \multicolumn{2}{|c|}{ 18. What would be the most challenging rotation with which to begin? ${ }^{\mathrm{b}}$} \\
\hline VA/county hospital & $22(26 \%)$ \\
\hline Comprehensive ophthalmology & $4(5 \%)$ \\
\hline Consult & $3(4 \%)$ \\
\hline Cornea & $4(5 \%)$ \\
\hline Glaucoma & $2(2 \%)$ \\
\hline Retina & $28(33 \%)$ \\
\hline Pediatric ophthalmology & $37(44 \%)$ \\
\hline Neuro-ophthalmology & $21(25 \%)$ \\
\hline Ocular pathology & $1(1 \%)$ \\
\hline Oculoplastics & $8(9 \%)$ \\
\hline Research & $1(1 \%)$ \\
\hline Other & $1(1 \%)$ \\
\hline \multicolumn{2}{|c|}{ 19. What would be the best rotation with which to begin? ${ }^{b}$} \\
\hline VA/county hospital & $23(26 \%)$ \\
\hline Comprehensive ophthalmology & $75(85 \%)$ \\
\hline Oculoplastics & $6(7 \%)$ \\
\hline Cornea & $6(7 \%)$ \\
\hline Glaucoma & $6(7 \%)$ \\
\hline Retina & $4(5 \%)$ \\
\hline Pediatric ophthalmology & $1(1 \%)$ \\
\hline Neuro-ophthalmology & $5(6 \%)$ \\
\hline Ocular pathology & $5(6 \%)$ \\
\hline \multicolumn{2}{|c|}{ 20. What would you have done differently prior to starting ophthalmology residency? ${ }^{\mathrm{b}}$} \\
\hline Nothing & $34(39 \%)$ \\
\hline More preparation & $45(52 \%)$ \\
\hline Rotation & $12(14 \%)$ \\
\hline Other & $1(1 \%)$ \\
\hline \multicolumn{2}{|c|}{ 21. How does the transition to ophthalmology residency compare with the transition to internship? } \\
\hline Much less stressful & $6(7 \%)$ \\
\hline Somewhat less stressful & $15(17 \%)$ \\
\hline Equally stressful & $12(14 \%)$ \\
\hline Somewhat more stressful & $32(36 \%)$ \\
\hline Much more stressful & $23(26 \%)$ \\
\hline
\end{tabular}

Abbreviations: EHR, electronic health record; VA, Veterans' Affairs.

${ }^{a}$ Questions 1 and 15 not included. Question 1 pertained to contact information, and question 15 asked respondents to rank stress level on a scale from 1 to 10 .

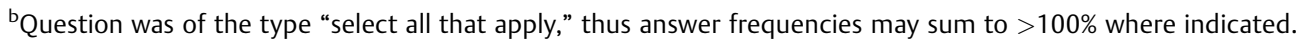


- Table 1 provides the wording of all survey questions and the proportion of respondents who selected each answer choice. Of note, 55 (63\%) respondents identified the transition to ophthalmologic training as "somewhat more" or "much more" stressful than the transition to internship. Sixty-six (73\%) spent less than 1 hour per week preparing for ophthalmology residency during internship, and 45 (52\%) wished they had done more. During orientation to ophthalmology residency, 64 (71\%) identified sessions dedicated to exam techniques as most helpful, and 25 (28\%) considered introductory lectures as least helpful. Residents wished that greater attention had been paid to common consult diagnoses ( $n=56,62 \%$ ), basic eye exam ( $n=38,42 \%$ ), and ocular trauma $(n=23,26 \%$ ) during orientation. With respect to exam techniques, there was a desire for greater detail in discussing gonioscopy $(n=66,73 \%)$ and the posterior segment examination, using both slit lamp $(n=36$, $40 \%$ ) and indirect ( $n=44,49 \%)$ ophthalmoscopy. However, most respondents felt comfortable with pupillary examination ( $n=65,73 \%)$, confrontational visual fields $(n=70,79 \%)$, and examination of the anterior segment ( $n=61,69 \%)$ following orientation. Finally, 68 (78\%) identified call as the most stressful aspect of early residency, and 75 (85\%) considered comprehensive ophthalmology the best rotation with which to begin.

Two-way tabulation showed a significant association between type of PGY-1 year and the amount of time spent preparing independently for ophthalmology residency (Fisher exact test, two-sided $p$-value $=0.01$ ). Specifically, respondents doing a transitional year tended to spend more time preparing than those doing a preliminary medicine or any other type of PGY-1 year.

The overall median stress level during the first 2 months of residency was 7 (scale from 1 to 10, 10 being highly stressful). - Table 2 displays relationships between various questions of interest and the level of stress experienced during early residency. Factors associated with significantly lower stress during this period included spending more time during PGY1 year preparing for ophthalmology residency (Kruskal-Wallis test, two-sided $p$-value $=0.02$ ). Specifically, independent preparation (Jonckheere test, two-sided $p$-value $=0.002$ ) and doing an ophthalmology rotation during internship (Jonckheere test, two-sided $p$-value $=0.04)$ significantly reduced stress, and those doing a transitional PGY-1 year were significantly more likely to do either (Kruskal-Wallis test, $p=0.008$ ). Residency orientations which spent relatively more time practicing hands-on skills (Jonckheere test, two-sided $p$-value $<0.01$ ), relationship-building sessions during orientation (Wilcoxon rank sum test, two-sided $p$-value $=0.05$ ), feeling adequately oriented to facilities and logistics following orientation (Jonckheere test, two-sided $p$-value $<0.01$ ), and having a longer buddy-call system (Kruskal-Wallis test, two-sided $p$-value $=0.04$ ) were also associated with significantly lower stress levels. There was no significant association between type of PGY-1 year (Kruskal-Wallis test, two-sided $p$-value $=0.79$ ), type of independent preparation for ophthalmology residency (Wilcoxon rank sum tests, two-sided Bonferroni-adjusted $p$-values ranged from 0.20 to $<0.99$ ), length of orientation (Jonckheere test, two-sided $p$-value $=0.14$ ), or time spent on didactic topics during orientation (Jonckheere test, two-sided $p$-value $=0.83$ ) and stress experienced during the first 3 months of ophthalmology residency. Among residents that did a transitional year, there was a nonsignificant trend toward lower stress among the group that did independent preparation (mean 6.3 vs. 8 on the 10 -point stress scale; $p=0.08$ ).

\section{Discussion}

This study aimed to assess the stress associated with beginning ophthalmology residency and identify potential interventions to help ease this transition. Key findings include the following: (1) time spent preparing for ophthalmology residency during PGY1 year is crucial to easing this transition; (2) a transitional PGY1 year affords more opportunity to prepare for ophthalmology residency than preliminary medicine or surgery; (3) orientations which provide more hands-on experience, relationship-building, and familiarity with logistics reduce stress among new residents, whereas longer orientations and didactic teaching do not; (4) longer buddy-call systems produce significantly lower stress; and (5) the majority of respondents would prefer starting residency with a comprehensive ophthalmology rotation.

Our data suggest that the majority of new first-year ophthalmology residents found the transition to ophthalmology residency more stressful than the transition to their PGY-1 year. However, devoting time during PGY-1 year to prepare for ophthalmology residency, even if for only 1 hour per week, significantly eased this transition. In retrospect, 45 (52\%) respondents wished they had done more such preparation. The demands of a PGY-1 year may leave little room in the schedule for significant independent study for the future ophthalmology resident. However, it is also possible that this low level of preparation is due to a lack of guidance. A preparatory curriculum, whether a web-based learning module or a reading syllabus during the PGY-1 year, could facilitate improved preparation for ophthalmology residency without adding undue burden.

Residents can also ease the transition to residency themselves via their selection of type of PGY-1 year. Those doing a transitional year were more likely to do independent preparation, such as reading and ophthalmology rotations, which were associated with less stress during the PGY-2 year. Doing a transitional year itself, however, was not associated with less stress. One possible reason for this disparity is that only a portion of residents doing a transitional year did independent preparation. Among those doing a transitional year, there was indeed a trend toward less stress in the group that did independent preparation. This approach may be especially helpful given the paucity of ophthalmology-specific training in medical school and internship. ${ }^{13-16}$ A few ophthalmology residency programs in the country $^{17,18}$ offer an integrated PGY-1 position for ophthalmology residents wherein residents have greater exposure to ophthalmology during their PGY-1 year. While this may reduce stress during their PGY-2 experience, it is also possible that this design may simply shift the stressful transition to the PGY-1 year. It may be important to consider a PGY-1 experience that allows for learning ophthalmology-specific clinical skills without the expectation of independent patient care, often demanded of a PGY-2 resident. 
e16 Improving the Transition to Ophthalmology Residency Thomas et al.

Table 2 Factors affecting stress level during the first 2 months of ophthalmology residency among 91 respondents across the United States in 2013

\begin{tabular}{|c|c|c|c|c|}
\hline Survey question & $N$ & $\begin{array}{l}\text { Stress level, }{ }^{\mathrm{a}} \\
\text { median (IQR) }\end{array}$ & Statistical test performed & Two-sided $p$-value \\
\hline \multicolumn{5}{|c|}{ 2. Which best describes your PGY-1 year? } \\
\hline Preliminary medicine & 48 & $8(4-8)$ & \multirow[t]{4}{*}{ Kruskal-Wallis test } & \multirow[t]{4}{*}{0.789} \\
\hline Transitional & 37 & $7(5-8)$ & & \\
\hline Preliminary surgery & 5 & $7(5-7)$ & & \\
\hline Other & 1 & $6(6-6)$ & & \\
\hline \multicolumn{5}{|c|}{ 3. What type of independent preparation did you do for ophthalmology residency? ${ }^{b}$} \\
\hline None & 28 & $8(7-8)$ & Rank sum test & $0.339^{c}$ \\
\hline Textbook & 34 & $7(6-8)$ & Rank sum test & $1.000^{c}$ \\
\hline Videos & 7 & $8(7-9)$ & Rank sum test & $0.235^{\mathrm{c}}$ \\
\hline Rotation & 48 & $6(4-8)$ & Rank sum test & $0.196^{\mathrm{C}}$ \\
\hline \multicolumn{5}{|c|}{ 4. On average, how many hours per week did you spend preparing for ophthalmology residency during your PGY-1 year? } \\
\hline$<1$ & 66 & $8(6-8)$ & \multirow[t]{4}{*}{ Kruskal-Wallis test } & \multirow[t]{4}{*}{$0.016^{\mathrm{d}}$} \\
\hline 1 to 5 & 22 & $5.5(4-8)$ & & \\
\hline $5-10$ & 1 & $1(1-1)$ & & \\
\hline$>10$ & 2 & $5(3-7)$ & & \\
\hline \multicolumn{5}{|c|}{ 5. How long was orientation at the start of ophthalmology residency? } \\
\hline$<1 \mathrm{wk}$ & 22 & $8(4-9)$ & \multirow[t]{3}{*}{ Jonckheere trend test } & \multirow[t]{3}{*}{0.138} \\
\hline 1 to $2 \mathrm{wk}$ & 54 & $7(5-8)$ & & \\
\hline$>2 \mathrm{wk}$ & 14 & $7(4-8)$ & & \\
\hline \multicolumn{5}{|c|}{ 6. What percentage of orientation was spent on didactic information? } \\
\hline$<25 \%$ & 20 & $7.5(4.5-8.5)$ & \multirow[t]{3}{*}{ Jonckheere trend test } & \multirow[t]{3}{*}{0.826} \\
\hline 25 to $50 \%$ & 38 & $7(5-8)$ & & \\
\hline$>50 \%$ & 31 & $7(6-8)$ & & \\
\hline \multicolumn{5}{|c|}{ 7. What percentage of orientation was spent practicing hands-on skills? } \\
\hline$<25 \%$ & 45 & $8(6-9)$ & \multirow[t]{3}{*}{ Jonckheere trend test } & \multirow[t]{3}{*}{$0.001^{\mathrm{d}}$} \\
\hline 25 to $50 \%$ & 38 & $6(5-8)$ & & \\
\hline$>50 \%$ & 7 & $4(3-8)$ & & \\
\hline \multicolumn{5}{|c|}{ 8. Was there a time slot dedicated to relationship-building during orientation? } \\
\hline Yes & 63 & $7(4-8)$ & \multirow[t]{2}{*}{ Rank sum test } & \multirow[t]{2}{*}{$0.046^{\mathrm{d}}$} \\
\hline No & 27 & $8(6-9)$ & & \\
\hline \multicolumn{5}{|c|}{ 9. Did you feel adequately oriented to facilities and logistics upon completion of orientation? } \\
\hline Yes & 43 & $5(4-8)$ & \multirow[t]{3}{*}{ Jonckheere trend test } & \multirow[t]{3}{*}{$<0.001^{\mathrm{d}}$} \\
\hline Somewhat & 42 & $8(7-9)$ & & \\
\hline No & 5 & $9(8-10)$ & & \\
\hline \multicolumn{5}{|c|}{ 17. Did you have a buddy-call system? If so, for how long? } \\
\hline No & 1 & $6(6-6)$ & \multirow[t]{5}{*}{ Kruskal-Wallis test } & \multirow[t]{5}{*}{$0.036^{\mathrm{d}}$} \\
\hline$<1 \mathrm{mo}$ & 24 & $8(6.5-9)$ & & \\
\hline 1 to $3 \mathrm{mo}$ & 49 & $7(5-8)$ & & \\
\hline 3 to $6 \mathrm{mo}$ & 9 & $7(4-8)$ & & \\
\hline$>6 \mathrm{mo}$ & 5 & $4(4-6)$ & & \\
\hline
\end{tabular}

Abbreviation: IQR, interquartile range.

${ }^{a}$ Median stress level during the first 2 months of ophthalmology residency, assessed by survey. Scale of 1 (not stressful) to 10 (extremely stressful).

${ }^{b}$ Answer choices were not distinct groups; respondents could check more than one answer. Each pairwise comparison is between those who selected the indicated answer and those who did not.

'Bonferroni-corrected.

${ }^{\mathrm{d}}$ Statistically significant at $\alpha=0.05$ level. 
Orientation to ophthalmology residency is another period where interventions have the potential to reduce the stress of this transition. The duration and focus of orientation at the start of ophthalmology residency was found to vary widely among respondents in this study. We found that residents undergoing orientations which provided more hands-on experience, relationship-building, and familiarity with logistics experienced significantly less stress than their counterparts, whereas longer orientations and didactic teaching had no effect on stress. Given these findings, residents would likely benefit from an orientation schedule with a greater emphasis on examination techniques, common pathology seen on consults, and logistical issues that they are likely to encounter.

Respondents identified call as the most stressful aspect of the first few months of ophthalmology residency. The majority of respondents had some duration of buddy-call system in place, wherein a senior resident assisted their new colleagues with after-hours patient care. We found that residents at programs with a longer duration of buddy call were significantly less stressed. While this places a greater burden on senior residents, a longer duration of supervised call appears to ease the transition to ophthalmology residency.

Lastly, 75 (85\%) respondents identified comprehensive ophthalmology as the "best" rotation with which to begin, while pediatric ophthalmology, retina, Veterans' Affairs/ county hospital, and neuro-ophthalmology were selected as the "most challenging" in the initial stages of residency. It is not feasible for most programs to start all residents with the same rotation. Some programs, however, offer a staggered schedule for residency start time, ${ }^{19}$ allowing each resident to start with the same rotation and have the same sequence of rotations throughout their training. While such a model could incorporate the results of this study to improve residents' experience during the first year, it may complicate the logistics of transitioning from internship or to fellowship. It is also possible that the difference in the stress experienced by the residents in different types of rotations could be related to other confounding factors, such as the level of independence and workload in different settings rather than the type of rotation. Future research may aim to address whether such confounders exist or why residents found some rotations more stressful than other.

This study did not assess whether a reduction in stress during early residency translates to better training or better patient care. In fact, it is possible that a certain degree of stress can facilitate the development of residents into capable ophthalmologists. However, the literature suggests that an impaired sense of physician wellbeing can lead to lower levels of empathy toward patients. ${ }^{20,21}$ As we conceive resident training to be not only the transfer of knowledge, but also the development of multidimensional competence, resident wellbeing and stress remain important issues even though knowledge acquisition and the sense of wellbeing have not been correlated. ${ }^{22}$ Furthermore, an improved sense of wellbeing early in residency may be important, as some authors have observed persistence of burnout for residents who experience this phenomenon early in their training. ${ }^{23}$
The main limitations of this study were the low response rate, possible nonresponse bias, and uncontrolled confounding factors due to the absence of demographic and program characteristics. While a response rate of $20 \%$ limits the generalizability of our results, it does fall within the range of prior published physician surveys. ${ }^{24}$ Further investigation on this topic with input from a larger proportion of residents is warranted. While commencing ophthalmology residency will likely always be somewhat stressful, this study indicates that there may be interventions that residents and residency programs can implement to reduce this burden during the PGY-2 year.

\section{Financial Support}

This work was funded by an unrestricted institutional grant from Research to Prevent Blindness (New York, NY). This research was also funded by the following grant: P30 EY010572 from the National Institute of Health (NIH, Bethesda, Maryland).

\section{Acknowledgment}

The authors would like to thank Dr. Dongseok Choi for his help with the statistical analysis.

\section{References}

1 Brennan N, Corrigan O, Allard J, et al. The transition from medical student to junior doctor: today's experiences of Tomorrow's Doctors. Med Educ 2010;44(5):449-458

2 Flynn SP, Hekelman FP. Reality shock: a case study in the socialization of new residents. Fam Med 1993;25(10): 633-636

3 Schneider SE, Phillips WM. Depression and anxiety in medical, surgical, and pediatric interns. Psychol Rep 1993;72 (3, Pt 2):1145-1146

4 Hurst C, Kahan D, Ruetalo M, Edwards S. A year in transition: a qualitative study examining the trajectory of first year residents' well-being. BMC Med Educ 2013;13:96

5 Teunissen PW, Westerman M. Opportunity or threat: the ambiguity of the consequences of transitions in medical education. Med Educ 2011;45(1):51-59

6 Shah M, Knoch D, Waxman E. The state of ophthalmology medical student education in the United States and Canada, 2012 through 2013. Ophthalmology 2014;121(6): $1160-1163$

7 Paice E, Rutter H, Wetherell M, Winder B, McManus IC. Stressful incidents, stress and coping strategies in the pre-registration house officer year. Med Educ 2002;36(1):56-65

8 Antonoff MB, Swanson JA, Green CA, Mann BD, Maddaus MA, D'Cunha J. The significant impact of a competency-based preparatory course for senior medical students entering surgical residency. Acad Med 2012;87(3):308-319

9 Meier AH, Henry J, Marine R, Murray WB. Implementation of a Web-and simulation-based curriculum to ease the transition from medical school to surgical internship. Am J Surg 2005;190(1): 137-140

10 Laack TA, Newman JS, Goyal DG, Torsher LC. A 1-week simulated internship course helps prepare medical students for transition to residency. Simul Healthc 2010;5(3):127-132 
e18 Improving the Transition to Ophthalmology Residency Thomas et al.

11 Mushin IC, Matteson MT, Lynch EC. Developing a resident assistance program. Beyond the support group model. Arch Intern Med 1993;153(6):729-733

12 SF Match Residency and Fellowship Matching Services. Ophthalmology residency match report. Available at: https://www.sfmatch.org/ SpecialtyInsideAll.aspx?id=6\&typ $=2 \&$ name $=$ Ophthalmology. Accessed March 19, 2014

13 Spivey BE. Ophthalmology for medical students: content and comment. Arch Ophthalmol 1970;84(3):368-375

14 Stern GA; The Association of University Professors of Ophthalmology Education Committee. Teaching ophthalmology to primary care physicians. Arch Ophthalmol 1995;113(6): 722-724

15 Jacobs DS. Teaching doctors about the eye: trends in the education of medical students and primary care residents. Surv Ophthalmol 1998;42(4):383-389

16 Quillen DA, Harper RA, Haik BG. Medical student education in ophthalmology: crisis and opportunity. Ophthalmology 2005; 112(11):1867-1868

17 Department of Ophthalmology \& Visual Sciences, University of Utah. Residency program. Available at: http://medicine.utah. edu/ophthalmology/education/residency/index.php. Accessed March 19, 2014
18 University of Iowa Health Care - Ophthalmology Residency. Integrated internship. Available at: http://www.uihealthcare.org/GME/InsidePages.aspx?id=241830\&taxid $=225135$. Accessed March 19, 2014

19 The Department of Ophthalmology at California Pacific Medical Center Residency Program. The staggered start. Available at: http://www.cpmc.org/professionals/education/residencies/ ophthalmology/apply.html. Accessed March 19, 2014

20 Passalacqua SA, Segrin C. The effect of resident physician stress, burnout, and empathy on patient-centered communication during the long-call shift. Health Commun 2012;27(5): 449-456

21 Beckman TJ, Reed DA, Shanafelt TD, West CP. Resident physician well-being and assessments of their knowledge and clinical performance. J Gen Intern Med 2012;27(3):325-330

22 West CP, Shanafelt TD, Cook DA. Lack of association between resident doctors' well-being and medical knowledge. Med Educ 2010;44(12):1224-1231

23 Campbell J, Prochazka AV, Yamashita T, Gopal R. Predictors of persistent burnout in internal medicine residents: a prospective cohort study. Acad Med 2010;85(10):1630-1634

24 Cummings SM, Savitz LA, Konrad TR. Reported response rates to mailed physician questionnaires. Health Serv Res 2001;35(6): 1347-1355 